\title{
Rituximab for the treatment of rheumatoid arthritis: an update
}

This article was published in the following Dove Press journal:

Drug Design, Development and Therapy

27 December 2013

Number of times this article has been viewed

\section{Chi Chiu Mok}

Department of Medicine, Tuen Mun Hospital, Hong Kong, Special Administrative Region of the People's Republic of China
Correspondence: Chi Chiu Mok Department of Medicine, Tuen Mun Hospital, New Territories, Hong Kong, Special Administrative Region of the People's Republic of China

Tel +852 24685389

Fax +85224569100

Emailccmok2005@yahoo.com
Abstract: Rituximab is a chimeric monoclonal antibody that targets the CD20 molecule expressed on the surface of B cells. It was first used in the treatment of non-Hodgkin's lymphoma and later approved for the treatment of rheumatoid arthritis (RA) that does not respond adequately to disease-modifying antirheumatic drugs, including the anti-tumor-necrosis-factor (TNF) biologics. Sustained efficacy in RA can be achieved by repeated courses of rituximab. However, the optimal dose and retreatment schedule of rituximab in RA remains to be established. Seropositivity, complete B cell depletion shortly after treatment, and previous failure to no more than one anti-TNF agent are three factors associated with greater clinical benefits to rituximab. Infusion reaction to the first dose of rituximab occurs in approximately $25 \%$ of RA patients, and the incidence reduces with subsequent exposure. Immunogenicity to the chimeric compound occurs in $11 \%$ of RA patients, but this does not correlate with its efficacy in B cell depletion. Extended observation of randomized controlled trials in RA does not reveal a significant increase in the incidence of serious infections related to rituximab compared to placebo groups, and the infection rate remains static over time. Repeated treatment with rituximab is associated with hypogammaglobulinemia, which may increase the risk of serious, but rarely opportunistic, infections. Reactivation of occult hepatitis B infection has been reported in RA patients receiving rituximab, but no increase in the incidence of tuberculosis was observed. Screening for baseline serum immunoglobulin $\mathrm{G}$ level and hepatitis B status (including occult infection) is important, especially in Asian countries where hepatitis B infection is prevalent. The rare but fatal progressive multifocal leukoencephalopathy linked to the use of rituximab has to be noted. Postmarketing surveillance and registry data, particularly in Asia, are necessary to establish the long-term efficacy and safety of rituximab in the treatment of RA.

Keywords: biologics, B-cell depletion, rheumatoid arthritis, prognosis

\section{Introduction}

The pathogenesis of rheumatoid arthritis (RA) remains enigmatic. Multiple genetic and environmental factors are likely to be involved in the susceptibility to RA development. ${ }^{1}$ The discovery of the rheumatoid factor (RF) in the 1940s and the abundance of plasma cells and activated B lymphocytes in the RA synovium emphasized the importance of $\mathrm{B}$ cells in the pathogenesis of the disease. ${ }^{2}$ However, work on B cells and autoantibodies waned over time when it was demonstrated that RF lacked sensitivity and specificity. Attention was shifted to other players of the immune system such as T cells, macrophages, dendritic cells, and fibroblasts. ${ }^{3}$ Revival of interest in the B cell pathogenesis of RA was related to the discovery of autoantibodies that direct against citrullinated peptides. ${ }^{4}$ Moreover, the success of B cell depletion therapy in the treatment of RA 
in the past decade has led to a renaissance of B cells as key mediators of RA. ${ }^{5}$

The precise contribution of $\mathrm{B}$ cells to the pathogenesis of RA is not well defined. ${ }^{6}$ In addition to the production of RF and other autoantibodies such as antibodies against citrullinated cyclic peptide (anti-CCP), B cells have many other potential roles. First, they can act as antigen-presenting cells by processing and presenting antigenic peptides to $\mathrm{T}$ cells, which are then activated to proliferate and exert proinflammatory activities. ${ }^{7}$ RF-producing B cells are particularly effective in presenting immune complexes to $T$ cells, regardless of the antigens contained in these complexes. ${ }^{8}$ Second, B cells are able to produce a number of proinflammatory cytokines such as interleukin (IL)-6, tumor necrosis factor (TNF)- $\alpha$ and lymphotoxin- $\beta,{ }^{9}$ as well as chemokines that can modulate migration and functions of the dendritic cells and CD4+ Th cells ${ }^{10}$ that are relevant to the pathophysiology of RA. RF may also perpetuate $\mathrm{B}$ cell activation, leading to further production of RF. This, together with RF immune-complex-mediated complement activation, may contribute to the sustained inflammatory response that aggravates joint damage. ${ }^{11}$

On the other hand, ectopic lymphoid structures ranging from loose aggregates of $\mathrm{T}$ and $\mathrm{B}$ cells to distinct follicle-like structures resembling germinal centers in close contact with the synovial membrane are present in up to $40 \%$ of patients with RA. ${ }^{12}$ Lymphotoxins and B cell specific chemokines such as CXCL13, CXCL12, and CCL19 produced by various cell types in these aggregates are crucial for promoting B cell migration and accumulation in tissue, and the formation of germinal centers within the synovium. ${ }^{12}$ Higher baseline levels of CXCL13 are associated with a lower efficacy of peripheral $\mathrm{B}$ cell depletion by rituximab and faster return of $\mathrm{B}$ cells. ${ }^{13}$

In recent years, a number of B-cell-depleting biological agents have been developed for the treatment of autoimmune diseases. However, rituximab is the only biologic marketed for specific B cell targeting therapy in RA. Other agents such as ocrelizumab, ofatumumab, belimumab, and atacicept were either found to be ineffective or withdrawn from further development because of safety concerns or no perceived advantage over rituximab. ${ }^{14}$ While it is out of the scope of this article to describe the cellular and molecular effects of rituximab in detail, updated information on the use of rituximab in the treatment of RA and its safety data are summarized.

\section{Mechanisms of action of rituximab}

Rituximab is a chimeric mouse/human monoclonal antibody that directs against the CD20 molecule on the surface of
B cells that express this marker. Mature B cells and B cell precursors from the early pre-B-cell to memory $\mathrm{B}$ cell stages are depleted by the compound. ${ }^{15}$ However, stem cells, pro-Bcells, and terminally differentiated plasma cells that do not express CD20 are not affected. Administration of rituximab leads to transient but almost complete depletion of B cells in the peripheral blood, and partial depletion of B cells in the bone marrow and synovial tissue. ${ }^{16}$ The Fc portion of rituximab mediates antibody-dependent cellular cytotoxicity, complement-mediated cytotoxicity, and apoptosis of the CD20+ B cells. ${ }^{15}$

Repopulation of the peripheral blood B cells usually occurs at 6-9 months after rituximab administration, and the time to reconstitution of the peripheral B cells depends on the clearance of the compound and the regenerative capacity of the bone marrow. ${ }^{17}$ Peripheral blood B cell repopulation after rituximab treatment is similar to what is observed after bone marrow transplantation, and predominantly involves a subset of naïve or antigenically inexperienced transitional $\mathrm{B}$ cells derived from an immature population. ${ }^{18}$ The degree of $\mathrm{B}$ cell depletion in the peripheral blood and synovium has been correlated positively with the clinical response of rituximab. ${ }^{19,20}$ Despite the fact that rituximab does not deplete fully matured plasma cells, repeated administration of the biologic frequently induces a reduction of immunoglobulins, particularly immunoglobulin $\mathrm{G}$ (IgG), which may carry an increased risk of infection. ${ }^{21}$

\section{Clinical trials of rituximab in RA}

The efficacy of rituximab in RA was first reported in 1998 by a group of UK investigators in an open-label trial, ${ }^{22}$ followed by confirmation by other case series. ${ }^{23,24}$ Subsequently, eight randomized controlled trials (RCTs) were conducted in patients with RA (Table 1). ${ }^{25-32}$

\section{Established RA}

\section{Methotrexate (MTX) or disease- modifying antirheumatic drug (DMARD) failures}

In the first randomized double-blind placebo-controlled trial, ${ }^{25} 161$ patients with long-standing RA and active disease that did not respond adequately to MTX were randomized to four treatment arms: 1) MTX alone; 2) rituximab monotherapy; 3) rituximab plus intravenous cyclophosphamide (CYC); or 4) rituximab plus MTX. Rituximab (1,000 mg) was administered intravenously on day 1 and day 15. After 24 weeks, the American College of Rheumatology (ACR)50 responses in the rituximab combination groups (with either 


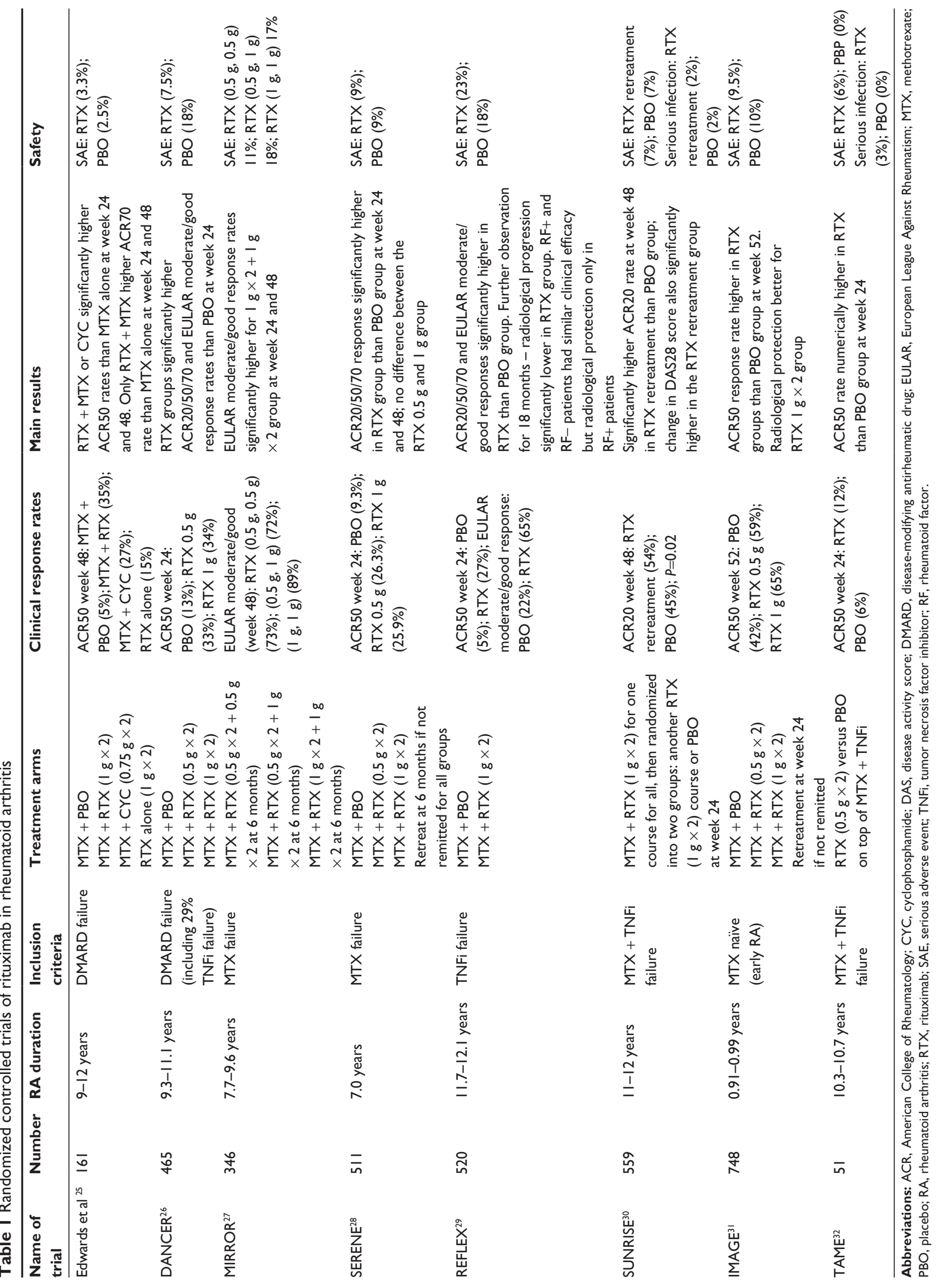


CYC or MTX) were significantly higher than that of MTX alone. The ACR50 responses remained significantly higher in the rituximab combination groups than MTX monotherapy at week 48 . The ACR70 response was only significantly higher in patients treated with the MTX-rituximab combination than MTX alone at week 48. Rituximab monotherapy was not significantly better than MTX alone in terms of the ACR50 and ACR70 response at week 24.

In a subsequent Phase IIb dose-ranging trial (DANCER), ${ }^{26}$ 465 patients with active long-standing RA refractory to DMARDs including the biological agents (in 29\% patients) were randomized to receive placebo, rituximab (two doses of $500 \mathrm{mg}$ ), or rituximab (two doses of $1,000 \mathrm{mg}$ ) on top of MTX. At week 24, significantly higher proportions of patients achieved ACR20/50/70 and European League Against Rheumatism (EULAR) moderate/good responses in the two rituximab groups than in the placebo arm. Primary analysis within the main effect model showed that the use of glucocorticoids as premedication did not affect the ACR20 response at week 24 , the primary endpoint.

The more recent Phase III study (MIRROR) ${ }^{27}$ randomized 346 patients with longstanding RA who did not respond to MTX to receive two courses (baseline and month 6) of three different dosing regimens of rituximab: 1) two doses of $500 \mathrm{mg}$, then two doses of $500 \mathrm{mg}$; 2) two doses of $500 \mathrm{mg}$, then two doses of 1,000 mg; or 3) two doses of 1,000 mg, then two doses of $1,000 \mathrm{mg}$. The ACR responses were similar among the three treatment arms at week 24, but the EULAR moderate/good response was significantly higher in the two doses of 1,000 mg, then two doses of 1,000 mg. At week 48, a higher proportion of patients treated with rituximab two doses of 1,000 mg, then two doses of 1,000 mg maintained or improved their week 24 responses. Dose escalation from two doses of $500 \mathrm{mg}$, then two doses of 1,000 mg did not appear to improve the clinical response as compared to the two doses of $500 \mathrm{mg}$, then two doses of $500 \mathrm{mg}$ regimen. All rituximab regimens demonstrated similar safety.

A similar multicenter Phase III RCT (SERENE) ${ }^{28}$ was carried out to test for the efficacy of two dosing regimens of rituximab. In this trial, a placebo group was included for comparison. A total of 511 RA patients with a mean disease duration of around 7 years who failed MTX treatment were randomized to receive placebo, rituximab (two doses of $500 \mathrm{mg}$ ), or rituximab (two doses of 1,000 mg) in combination with MTX. Open-label rituximab treatment was given to patients who failed to remit at week 24 - rituximab patients were given repeat infusion of their randomized doses and placebo patients were given rituximab rescue (two doses of $500 \mathrm{mg}$ ). At week 24 and 48, both doses of rituximab showed statistically superior efficacy to placebo. Both rituximab doses did not differ significantly in the efficacy and safety outcomes.

\section{Anti-TNF failures}

The REFLEX study was a Phase III RCT to test the efficacy of rituximab in anti-TNF failures. ${ }^{29} \mathrm{~A}$ total of 520 RA patients with longstanding disease who failed at least one anti-TNF biologic were randomized in a 3:2 ratio to receive either rituximab (two doses of $1,000 \mathrm{mg}$ ) or placebo infusions, both with background MTX. At week 24, the ACR20/50/70 and EULAR moderate/good responses were significantly more frequent in the rituximab group than in the placebo group of patients. Patients in the REFLEX study were further followed up for 18 months. Placebo-treated patients could be rescued and rituximab-treated patients could receive further courses of the drug. At 2 years, progression of radiological damage was significantly lower in the rituximab plus MTX group compared to the MTX alone group..$^{33}$ Among the rituximab-treated patients, $87 \%$ who did not have radiological progression at 1 year continued to have no progression at 2 years.

To further evaluate whether retreatment with rituximab would confer benefits in anti-TNF failures, 559 RA patients who failed to respond to one or more anti-TNF agents in combination with MTX were studied (SUNRISE).$^{30}$ All patients received an open-label course of rituximab (two doses of $1,000 \mathrm{mg}$ ) on top of MTX. At week 24, those who failed to achieve Disease Activity Score (DAS)28 remission were randomized to receive another course of rituximab or placebo in a 2:1 ratio. Relative to baseline, patients who received rituximab retreatment had significantly improved efficacy at week 48 compared to placebo infusion. The authors concluded that two courses of rituximab about 6 months apart were associated with better and sustained efficacy at 1 year as compared to one course.

A Phase IIIb open-label prospective study was performed in 112 RA patients from 36 centers in Sweden and Canada (RESET) ${ }^{34}$ Patients with active RA but who failed to respond or were intolerant to a single anti-TNF agent were recruited to receive two infusions of rituximab $(1,000 \mathrm{mg})$. Retreatment of rituximab was given in $69 \%$ of patients between week 24 and 48 (mean time to retreatment was 8.5 months). The overall ACR responses at week 24 were similar to those reported in the REFLEX trial ${ }^{29}$ and the clinical response was sustained with retreatment. With stratification of patients according to RF status, it was demonstrated that the clinical 
efficacy of rituximab was superior in RF positive than RF negative patients.

A prospective 3-year observational study of 1124 RA patients (MIRAR) who discontinued at least one anti-TNF agent reported that the improvement in disease activity score at months 6,9 , and 12 was no different between those shifted to rituximab $(\mathrm{N}=591)$ and an alternative anti-TNF agent $(\mathrm{N}=533)$, after adjustment of baseline clinical characteristics by propensity scores. ${ }^{35}$ However, the results of this study have to be interpreted with caution as there was no randomization of the treatment arms and patient selection bias was bound to occur.

\section{Early RA}

A Phase III RCT (IMAGE) focused on MTX naïve patients with early RA. ${ }^{31}$ This study recruited 748 patients with active RA ( $83 \%$ with disease duration $<2$ years) who were randomized to receive MTX in combination with one of the following treatment arms: 1) placebo infusion; 2) rituximab (two doses of $500 \mathrm{mg}$ ); or 3) rituximab (two doses of 1,000 mg). Most patients ( $80 \%-84 \%$, balanced across treatment groups) had received a second course of treatment ( $80 \%$ by week 30$)$. At week 52, treatment with rituximab two doses of 1,000 $\mathrm{mg}$ or two doses of $500 \mathrm{mg}$ plus MTX was associated with better ACR50 responses when compared to MTX alone. However, a significant reduction in the progression of joint damage was only observed in the rituximab two doses of 1,000 $\mathrm{mg}$ group as compared to placebo. A further 12-month follow-up of patients showed that the rituximab two doses of $1,000 \mathrm{mg}$ group continued to maintain radiological joint damage inhibition compared to MTX alone. ${ }^{36}$ However, contrary to the 1-year result, exploratory analysis of the rituximab two doses of $500 \mathrm{mg}$ group showed that progressive joint damage was also retarded as compared to MTX alone. Although this study was not powered to compare between rituximab doses, exploratory results showed a trend of more radiological protection with the higher dose, which is clinically relevant in RA patients with early disease.

\section{Rituximab in combination with other biologics}

A combination of biological agents has been evaluated in RA. ${ }^{37,38}$ An early study did not reveal any additional clinical benefits of anakinra (an IL-1 receptor antagonist) in combination with etanercept (a TNF- $\alpha$ inhibitor) compared to etanercept alone in RA patients who failed to respond to MTX. ${ }^{37}$ However, the risk of infection was increased in the combination group. Similarly, a more recent study (ASSURE) showed an increased incidence of serious adverse events and serious infections with abatacept treatment in combination with another biological agent in patients with RA. ${ }^{38}$

The role of rituximab in combination with anti-TNF agents was assessed in a 24-week randomized controlled study (TAME). ${ }^{32}$ In this study, 51 active RA patients were randomized in a 2:1 ratio to receive either rituximab (two doses of $500 \mathrm{mg}$ ) or a placebo infusion on top of background MTX and an anti-TNF agent (etanercept or adalimumab). The primary outcome at week a 24 was safety. Although there were no new safety signals observed with rituximab combined with a TNF inhibitor, a clear clinical efficacy advantage of this combination strategy could not be demonstrated either.

\section{Rituximab and extra-articular manifestations of RA}

There is a paucity of data regarding the efficacy of rituximab in extra-articular manifestations of RA. In major RCTs of rituximab, RA patients with significant systemic manifestations were excluded. Isolated reports of the benefits of rituximab in RA patients with vasculitis, keratitis, scleritis, amyloidosis, pulmonary nodules, or Felty's syndrome could be found in the literature, although publication bias cannot be excluded. ${ }^{39-41}$

\section{Optimal dosing regimen of rituximab}

The optimal dosing regimen of rituximab in RA has not been established. In two RCTs, DANCER ${ }^{26}$ and SERENE, ${ }^{28}$ no significant differences in the clinical response of the two doses of rituximab (two doses of $500 \mathrm{mg}$ versus two doses of 1,000 mg) could be demonstrated in MTX inadequate responders. In the MIRROR study, ${ }^{27}$ however, the higher rituximab dose group (two doses of 1,000 mg) was associated with a better and sustained clinical response at week 48. In MTX naïve early RA patients (IMAGE study), MTX in combination with rituximab (two doses of $1,000 \mathrm{mg}$ ) was not significantly more effective than a lower rituximab dose (two doses of $500 \mathrm{mg}$ ) at week 52 in terms of ACR and EULAR responses. ${ }^{31}$ A recent meta-analysis on the above four RCTs did not demonstrate a significant difference in the clinical responses between the high- and low-dose rituximab regimens. ${ }^{42}$

Vital et $\mathrm{al}^{19}$ correlated the degree of $\mathrm{B}$ cell depletion after rituximab therapy for RA with the clinical response achieved. While complete depletion of B cells at week 2 was more common with the higher rituximab dose (two doses of $1,000 \mathrm{mg}$ ), a quarter of patients treated with a lower dose 
of rituximab (two doses of $500 \mathrm{mg}$ ) had complete B cell depletion, which was associated with a good clinical response at 6 months. It was concluded that it was the degree of B cell depletion instead of the rituximab dose that was associated with clinical efficacy. As the response of individuals to rituximab-induced $\mathrm{B}$ cell depletion is likely to be heterogeneous, if not genetically determined, and dependent on many other factors such as the baseline B cell number, it is difficult to select patients who will benefit from a lower and hence more cost-effective dose of rituximab. Perhaps analysis of B cell subsets before and after rituximab treatment, which is not routinely available in many centers, may guide the dose of subsequent courses of rituximab retreatment.

In early RA patients, a higher dose of rituximab (two doses of $1,000 \mathrm{mg}$ ) in combination with MTX showed a better efficacy in halting radiological progression than a lower dose of rituximab (two doses of $500 \mathrm{mg}$ ) when compared to MTX alone, although a lower dose of rituximab itself was associated with a significant difference in progression of radiological damage compared with placebo. ${ }^{31,36}$ As erosion occurs early in the course of the disease, ${ }^{43}$ prevention of radiological progression with the use of a higher dose of rituximab seems to be logical in patients with early RA. In patients who are refractory to the anti-TNF biologics, a lower dose of rituximab (two doses of $500 \mathrm{mg}$ ) has not been tested for radiological progression, whereas efficacy in slowing radiological damage has been shown with the higher dosing regimen (two doses of $1,000 \mathrm{mg}$ ). ${ }^{33}$

Thus, for RA patients who failed to respond adequately to anti-TNF agents, a higher dose of rituximab (two doses of $1,000 \mathrm{mg}$ ) is deemed more appropriate. In early RA patients or those who did not respond adequately to MTX or other DMARDs, the evidence to date also favors the use of a higher dose of rituximab.

\section{Retreatment schedule with rituximab}

The optimal timing for rituximab retreatment remains a research question. Options include treatment on flare, regular retreatment (eg, every 6 months), treatment with any deterioration, or treatment-to-target. ${ }^{44}$ Retrospective data supported a treatment-to-target strategy, ${ }^{45}$ whereas regular retreatment regardless of the disease activity might risk overtreatment in some patients that may lead to an increased rate of infective complications. ${ }^{44}$

In clinical studies, rituximab was given per protocol at baseline and then every 6 months. ${ }^{27,28,30}$ Clinical response is typically observed 3-4 months after the first course of rituximab. However, the durability of the clinical response is variable and often unpredictable in different patients. A prospective study showed that the mean time for rituximab retreatment since baseline was around 8.5 months in antiTNF failure RA patients. ${ }^{34}$ The rituximab insert package in the US states that retreatment can be given every 6 months according to clinical evaluation, but not sooner than every 4 months. ${ }^{5}$ The latest European consensus statements on use of rituximab in RA suggested that retreatment of rituximab might be considered after at least 24 weeks in patients who did not achieve clinical remission or at least low disease activity state as evidenced by any disease activity index. ${ }^{44}$ Otherwise, retreatment should be delayed until disease activity returned.

\section{Rituximab as monotherapy in RA}

An early RCT suggested that rituximab monotherapy was inferior to rituximab in combination with MTX or CYC, and was not significantly more efficacious than MTX alone in patients with established RA. ${ }^{25}$ Subsequent RCTs showed that rituximab in combination with MTX was superior to MTX alone in both established (SERENE) ${ }^{28}$ and early RA patients (IMAGE). ${ }^{31}$ In patients who did not respond adequately to the anti-TNF agents, rituximab in combination with MTX was more effective than MTX alone in established RA (REFLEX). ${ }^{29}$ A pooled analysis of ten European registries (CERERRA collaboration) involving 1,195 RA patients reported that rituximab in combination with either MTX or leflunomide (LEF) showed significantly higher rates of EULAR good response at 6 months compared to rituximab monotherapy. ${ }^{46}$ This study also suggested that rituximab could be combined with LEF in patients who were intolerant to or contraindicated for MTX to enhance clinical efficacy.

\section{Factors associated with clinical response to rituximab in RA}

A number of studies have attempted to identify predictors for better response in RA patients receiving rituximab therapy. Pooling of data from ten European registries revealed that among 2,019 patients with RA treated with rituximab, independent predictors for a EULAR good response at 6 months were anti-CCP positivity, lower number of previous DMARDs, $\leq$ one previous biological agent, and lower baseline DAS28 level. ${ }^{47}$ Patients with more complete depletion of peripheral B cells 2 weeks after rituximab infusion were more likely to respond better clinically. ${ }^{19,48}$ Other studies confirmed that patients who were negative for anti-CCP or those who failed more than one anti-TNF agent were associated with 
poorer clinical response. ${ }^{49,50}$ Efficacy appeared to be the best when rituximab was used as the first biological agent or after failure of no more than one anti-TNF agent. ${ }^{47}$

Another 6-month open-label study of refractory RA in France revealed that presence of anti-CCP antibodies or $\mathrm{RF}$, and an elevated serum $\operatorname{IgG}$ level were independently associated with better clinical response. ${ }^{51}$ Among 1,008 patients who participated in the REFLEX and SERENE studies, seropositivity (RF or anti-CCP) together with elevated $\mathrm{C}$-reactive protein at baseline was associated with a better clinical response to rituximab. ${ }^{52}$ In the IMAGE trial (MTX-naïve early RA patients), RF and/or anti-CCP positive patients treated with rituximab plus MTX were more likely to have an ACR50 response and no radiographic progression compared with those receiving MTX alone. ${ }^{31}$ However, in seronegative patients, rituximab treatment had a less pronounced effect on radiographic progression and no effect on clinical response. Finally, in the REFLEX trial, although a response was observed in seronegative RA patients, protection from joint damage was only evident in the seropositive subgroup..$^{29,44}$

It was shown earlier that clinical response of RA to rituximab therapy was preceded by a significant reduction of peripheral blood and marrow CD27+ memory B cells. ${ }^{53}$ Another study demonstrated that patients who relapsed on return of B cells after rituximab therapy were more likely to show repopulation with higher numbers of memory B cells. ${ }^{54}$ Möller et a ${ }^{55}$ also confirmed that a low number of circulating CD27+IgD- class-switched memory B cells during B cell repopulation was associated with a better clinical response to rituximab.

More recent studies have suggested novel genetic factors or biomarkers that influence the clinical response to rituximab in patients with RA. These include the Fc $\gamma$ receptor type IIIA polymorphism, ${ }^{56}$ promoter polymorphism of the B cell activation factor $(B A F F)$ gene, ${ }^{57} \mathrm{IL}-6$ gene polymorphism, ${ }^{58}$ baseline frequency of CD27+ memory B cells, ${ }^{59}$ levels of the B cell chemokines CCL19 ${ }^{60}$ and CXCL13, ${ }^{13}$ and baseline blood messenger RNA level of IgJ, a molecular marker for antibody-secreting plasmablasts. ${ }^{61}$

\section{Immunogenicity of rituximab in RA}

As rituximab is a chimeric monoclonal antibody, the development of human anti-chimeric antibodies (HACAs) that lower the level of the drug and hence its clinical efficacy is a concern. In the first RCT conducted by Edwards et al, ${ }^{25}$ HACAs were reported in $4.3 \%$ of patients who received rituximab. However, no breakdown figures were available for the rituximab monotherapy group in comparison with the combination groups. Thus, whether combining rituximab with MTX or CYC might reduce the incidence of HACAs is unclear. In subsequent RCTs, rituximab was exclusively used in combination with MTX. The incidence of HACAs to rituximab ranged from $2.7 \%$ to $7.9 \% .{ }^{26-30} \mathrm{~A}$ pooled analysis on the long-term safety of rituximab in clinical trials (2,578 patients) revealed that HACAs were present in $11 \%$ of patients on at least one visit. ${ }^{62}$ There was no obvious relationship between the dose of rituximab used (500 $\mathrm{mg}$ versus $1,000 \mathrm{mg}$ ) and the incidence of the HACA response. Interestingly, HACAs to rituximab were also detected in $3.6 \%$ of placebo-treated patients in the SERENE study. ${ }^{28}$ The presence of HACAs to rituximab does not appear to affect the efficacy of rituximab in depleting B cells, clinical efficacy at the study endpoints, and retreatment efficacy. There is also no obvious relationship between the HACA response and the occurrence of infusion reactions to rituximab.

\section{Safety concerns of rituximab}

Table 2 summarizes the safety data of rituximab in the treatment of RA based on pooled analyses of RCTs or registries.

Table 2 Safety of rituximab in rheumatoid arthritis patients (pooled data from randomized controlled trials/registries)

\begin{tabular}{|c|c|}
\hline Adverse event & Pooled incidence \\
\hline Infusion reaction & $\begin{array}{l}25 \% \text { during first infusion; usually mild } \\
\text { to moderate in severity; reduced } \\
\text { incidence on subsequent infusions }\end{array}$ \\
\hline Immunogenicity & $\begin{array}{l}\text { II\%; no relationship with efficacy of } \\
\text { B cell depletion, infusion reaction, } \\
\text { initial or retreatment clinical efficacy }\end{array}$ \\
\hline Hypogammaglobulinemia & $\begin{array}{l}\text { Low serum IgM ( } 22.4 \%) \text {, IgG }(3.5 \%) \text {, } \\
\text { or IgA (I.I\%) levels for more than } \\
4 \text { months; serious infections more } \\
\text { common in those with low lgG levels }\end{array}$ \\
\hline Serious infection & $\begin{array}{l}3.94 / 100 \text { patient-years; comparable to } \\
\text { those treated with methotrexate or } \\
\text { placebo in controlled trials; infection } \\
\text { rate static over } 5 \text { years of treatment; } \\
\text { serious opportunistic infection rare } \\
(0.06 / 100 \text { patient-years })\end{array}$ \\
\hline Herpes zoster reactivation & $\begin{array}{l}9 / 1,000 \text { patient-years, similar to those } \\
\text { treated with MTX alone and the } \\
\text { general population }\end{array}$ \\
\hline Tuberculosis & $2 / 3,194$ cases $(0.06 \%)$ \\
\hline Hepatitis B infection & $\begin{array}{l}\mathrm{I} / 3,194 \text { case }(0.03 \%) \text { of new hepatitis } \mathrm{B} \\
\text { infection; no cases of hepatitis } \mathrm{B} \\
\text { reactivation reported }\end{array}$ \\
\hline $\begin{array}{l}\text { Progressive multifocal } \\
\text { leukoencephalopathy }\end{array}$ & Rare (2.3/I00,000 patient-years) \\
\hline
\end{tabular}




\section{Infusion reaction}

In the oncology literature, around one-third of patients develop an infusion reaction to their first rituximab infusion despite premedication with glucocorticoids. ${ }^{63}$ Infusion reactions become less common during subsequent infusions. These reactions are usually mild to moderate but may require additional interventions such as paracetamol, antihistamines, bronchodilators, and further doses of glucocorticoids. Severe infusion reactions leading to drug withdrawal are uncommon $(<1 \%){ }^{44}$ Pooling of data from RCTs of rituximab in RA revealed that first infusion reactions occurred in approximately $25 \%$ of patients. ${ }^{44,62}$ Most reactions were mild to moderate in severity, with the most common symptoms being headache, skin itchiness, throat irritation, flushing, rash, hypertension, and pyrexia. The rates of infusion reaction in the second, third, fourth, and fifth course of rituximab were $13 \%, 9 \%, 9 \%$, and $3 \%$, respectively. ${ }^{62}$

\section{Serious infections}

In the rituximab RCTs DANCER and REFLEX, the rate of serious infections (excluding opportunistic infections and tuberculosis [TB]) was numerically higher for the two doses of 1,000 mg rituximab groups than the placebo groups. ${ }^{26,29}$ However, in the IMAGE trial, serious infection was not more common in the rituximab group than the placebo group of patients. ${ }^{31}$ A meta-analysis of three rituximab RCTs did not reveal an increase in serious infection rate of rituximab compared with placebo. ${ }^{64}$ Another study showed that the rate of hospitalized infection was similar in users of infliximab and rituximab. ${ }^{65}$

Registry data from the French Society of Rheumatology reported that the serious infection rate related to the use of rituximab in 1,303 RA patients was higher during the initial months (79\% in first 6 months) and was similar to that of other rituximab RCTs. ${ }^{21}$ Chronic pulmonary/heart disease, extra-articular involvement, and low $\operatorname{IgG}$ before rituximab treatment were independent risk factors for serious infections.

A pooled analysis of the long-term safety of rituximab in global clinical trials recently reported that among 3,194 patients who had received up to 17 rituximab courses over 9.5 years (11,962 patient-years), the rate of serious infections remained static over time and multiple courses of administration. ${ }^{66}$ The overall serious infection rate was 3.94/100 patient-years, which was comparable with patients treated with MTX and placebo (3.79/100 patientyears). Serious opportunistic infections were rare. The infection rate was similar in patients who were observed for more than 5 years. The most frequently reported infections $(>5 \%)$ in rituximab users were upper respiratory tract infections, nasopharyngitis, urinary tract infections, bronchitis, sinusitis, influenza, and gastroenteritis, and the serious infections most often occurred in the lower respiratory tract (pneumonia) (2\%). There was no increase in serious infection rates in patients who received subsequent biological therapies including the anti-TNF agents following rituximab treatment. Vascular events and malignancy rates were not higher than those reported in the general RA population.

\section{Rituximab-induced \\ hypogammaglobulinemia}

It is well recognized that repeated courses of rituximab are associated with secondary hypogammaglobulinemia. ${ }^{66,67} \mathrm{In}$ an open-label extended analysis of three RCTs of rituximab in 1,039 RA patients, the proportion of patients with serum IgM below the lower limit of the normal range was $10.3 \%$ at week $24,18.5 \%$ after the second course, and $23.5 \%$ after the third course.$^{67}$ A similar pattern was observed for IgG: $1.5 \%$ had levels below the lower limit of normal at week 24 , $4.3 \%$ after the second course, and $5.9 \%$ after the third course. However, serious infection rates in patients with low IgM (5.6/100 patient-years) or IgG (4.8/100 patient-years) were similar to those with normal immunoglobulin levels (4.7/100 patient-years).

A long-term safety report of rituximab in RA clinical trials described that among 3,194 rituximab-treated RA patients followed for more than 9.5 years, $22.4 \%$ developed low IgM, 3.5\% had low IgG levels, and 1.1\% had low IgA for $\geq 4$ months. ${ }^{66}$ No increase in infection rates was observed in patients during or after development of low IgM or IgG. However, serious infection was more frequent in patients with low IgG than those who never developed low IgG. These patients had older age, longer RA duration, lower mean CD19+ B cell count, lower mean IgG level, and had received more nonbiologic DMARDs at baseline. As mentioned previously, low baseline IgG level has also been identified as an independent risk factor for serious infections in the French registry. ${ }^{21}$

The long-term consequences of hypogammaglobulinemia induced by repeated courses of rituximab are still unclear. It is advisable to check baseline immunoglobulin levels before rituximab treatment. In patients with reduced IgG levels at baseline, alternative treatment options should be considered. Serum immunoglobulin levels should be regularly monitored in long-term users of rituximab. Discontinuation of rituximab should be considered when the IgG level drops progressively 
to below the lower limit of the normal range, particularly in high-risk individuals such as older patients, those receiving concomitant glucocorticoids, and those with multiple comorbidities. Recurrent infections related to rituximabinduced prolonged hypogammaglobulinemia might require intravenous immunoglobulin therapy. ${ }^{68,69}$

\section{Infections of special attention}

In the long-term rituximab in RA safety report, ${ }^{66}$ serious opportunistic infections were rarely reported (atypical pneumonia of unknown organisms [N=2]; Candida septicemia $[\mathrm{N}=1]$; pharyngeal abscess with unspecified organism $[\mathrm{N}=1]$; Scedosporium pneumonia $[\mathrm{N}=1]$; Pneumocystis jirovecii pneumonia $[\mathrm{N}=1]$; progressive multifocal leucoencephalopathy $[\mathrm{PML}][\mathrm{N}=1])$, corresponding to a rate of $0.06 / 100$ patientyears. Two cases of pulmonary TB were reported, but no cases of extra-pulmonary TB, atypical mycobacterial infection, or multidrug-resistant TB were observed. Moreover, no patients had hepatitis $B$ reactivation, but there was one case of de novo hepatitis B infection. In the all exposure population, 108 cases of herpes zoster were reported in 100 patients, giving a rate of 9.0/1,000 patient-years, which was similar to that of the MTX plus placebo group (11.7/1,000 patient-years) and the general RA populations (11.5/1,000 patient-years).

Only several isolated cases of reactivation of hepatitis $B$ (including occult hepatitis B infection) were reported in RA patients receiving rituximab in the literature. ${ }^{70-72}$ None of these cases came from high prevalence areas like Asian countries.

There is no evidence to suggest that reactivation of TB occurs more frequently in RA patients receiving rituximab. ${ }^{21,66}$ In fact, a recent study of 56 RA patients from Taiwan did not report any cases of TB reactivation after rituximab treatment for 1 year. ${ }^{73}$ Also, no significant change in released interferon gamma levels on a QuantiFERON-TBGold assay was observed in patients with latent TB infection $(\mathrm{N}=7)$ or in those with previous TB infection related to antiTNF agents $(\mathrm{N}=6)$ after rituximab therapy. It was suggested that rituximab might be an alternative agent for patients with high risk of TB reactivation.

PML is a rare but severe infection of the brain caused by the John Cunningham virus, characterized by progressive inflammation and demyelination of the white matter at multiple sites. No effective treatment is available and mortality is high. ${ }^{74}$ In a review of 38 cases of PML in nonhuman-immunodeficiency-virus (HIV) patients, mortality was reported in $71 \%$ of patients and the median time from onset of symptoms to death was 8 months. ${ }^{75}$
Cases of PML have been reported with rituximab use in RA patients. ${ }^{14,44,76,77}$ Most cases had longstanding disease with multiple immunosuppressive therapies in the past. Some patients had lymphopenia before rituximab treatment and concomitant cancer disorders. A large population-based study in the US reported only three cases of PML in more than 2 million patients with autoimmune diseases $(0.2 / 100,000$ patients $)$ who were receiving biological therapies but without underlying HIV infection or malignant disorders. ${ }^{78}$ Two patients were treated with rituximab, whereas another patient was treated with infliximab. The Swedish registry reported an insignificant increase in the rate of PML in 66,278 RA patients (1.0/100,000 person-years) compared to the general population (0.3/100,000 person-years). ${ }^{79}$ Among RA patients exposed to biologics, only one case of PML related to rituximab use was reported (rate: 2.3/100,000 person-years), confirming the rarity of this infection.

\section{Consensus statements on the use of rituximab in RA}

The Rituximab Consensus Expert Committee (Europe) published the updated recommendations for the use of rituximab in RA in $2011 .^{44}$ They recommend the use of rituximab in RA patients who have an inadequate response or intolerance to one or more anti-TNF biologics, in conjunction with MTX. LEF is a viable alternative when patients are intolerant to MTX. ${ }^{46}$ Although patients who are contraindicated for antiTNF therapy have not been adequately studied, one-fifth of RA patients in registries had received rituximab as their first biological therapy. ${ }^{44}$ As seropositive RA patients are more likely to respond better to rituximab, alternative treatment approaches should be considered for seronegative patients. In clinical studies of TNF inhibitor failure patients, rituximab was started as soon as 8 weeks after the last dose of infliximab or adalimumab and 4 weeks after the last dose of etanercept. The standard dose of rituximab is $1,000 \mathrm{mg}$ per intravenous infusion on day 1 and day 15. The clinical benefit or equivalence in terms of radiological progression of a lower dose of $500 \mathrm{mg}$ per infusion, particularly in patients who are refractory to anti-TNF agents, has not been confirmed. Intravenous methylprednisolone (100 mg) as premedication to rituximab infusion should be given to reduce the frequency and severity of infusion reactions. This is particularly important for the first infusion but can also be given before subsequent infusions. Paracetamol and antihistamines have also been routinely given in clinical trials before rituximab infusions. The consensus recommendations also suggest rituximab retreatment for patients who do not achieve remission or a 
low disease activity state after at least 6 months of infusion (treat-to-target principle). ${ }^{44}$

Before commencement of rituximab, a detailed medical history that includes allergies, medical comorbidities, and recurrent infections should be taken and a complete physical examination should be performed to consider possible contraindications. Hepatitis B and C serologies and liver function tests should be routinely performed. Reactivation of occult hepatitis B infection (surface antigen of the hepatitis $B$ virus [HBsAg] negative but total hepatitis B core antibody [anti-HBc] IgG positive) has been reported in the oncology literature, ${ }^{80-82}$ but only several case reports were published in patients with RA treated with rituximab. ${ }^{70-72}$ Thus, both HBsAg and anti-HBc IgG should be routinely obtained and hepatitis B virus (HBV) DNA titers should be determined when the latter is positive. HBsAg and anti-HBc IgG negativity identifies those who require vaccination before rituximab therapy, whereas HBsAg positive patients and/or anti-HBc positivity should be treated prophylactically. However, in our locality, we do not generally recommend using rituximab in patients who are hepatitis B carriers (HBsAg positive) unless there are absolutely no alternatives and close monitoring by the hepatologists after appropriate antiviral therapy is available. The management of occult hepatitis B infection in rituximab users remains unclear. HBsAg negative but anti-HBc positive patients with undetectable HBV DNA titers are not contraindicated to rituximab. Close monitoring to detect a rise of HBV DNA is mandatory and prophylactic antiviral treatment should be considered with the opinion of hepatologists. Patients with elevated HBV DNA titers should be referred to hepatologists for antiviral treatment.

On the other hand, there are conflicting perspectives regarding the consequence of rituximab-containing chemotherapy in chronic hepatitis $\mathrm{C}$ patients reported in the oncology literature. ${ }^{83}$ Some experts propose that rituximab may enhance the hepatic replication of the virus, followed by a spontaneous decrease once treatment is reduced or discontinued ${ }^{84,85}$ The consequent restoration of immune control may induce a hepatic flare of varying severity, ranging from no symptoms to life threatening fulminant hepatitis, probably reflecting the extent of cell-mediated hepatocellular necrosis. These clinical consequences are more likely when patients are treated with combined glucocorticoids and rituximab. Thus, for chronic carriers of hepatitis $\mathrm{C}$, collaboration with a hepatologist is necessary to decide for the best treatment plan for both the RA and viral disease.

Before rituximab therapy, enquiry about symptoms of TB and a routine chest radiograph is necessary.
Patients with active TB should be treated and rituximab should not be initiated. There is no evidence to indicate the need to screen for latent TB systematically in RA patients before rituximab therapy. ${ }^{44}$

In addition to routine laboratory tests performed in RA patients, baseline immunoglobulin levels should be obtained before rituximab therapy as reduced $\operatorname{IgG}, \operatorname{IgM}$, and $\operatorname{IgA}$ levels were reported with repeated rituximab courses. ${ }^{66,67}$ Moreover, low baseline IgG level was a risk factor for severe infections after rituximab treatment. ${ }^{21,62,66}$ Thus, monitoring of the immunoglobulin levels at baseline and longitudinally before each rituximab cycle is recommended.

Several studies have investigated the efficacy of vaccination in RA patients receiving rituximab. The humoral responses to influenza and pneumococcal vaccination were found to be seriously diminished in patients receiving rituximab treatment on top of DMARDs. ${ }^{86-90}$ Thus, it is recommended that inactivated vaccines such as influenza, pneumococcus, tetanus toxoid, and hepatitis B should be given at least 4 weeks prior to rituximab therapy ${ }^{44}$ More safety data are needed for the administration of live vaccines in rituximab users. At this juncture, they should be avoided.

Contraindications to rituximab include hypersensitivity to rituximab or other murine proteins, active serious infections, and severe heart failure. ${ }^{44}$ The safety of rituximab in children with rheumatic diseases has not been established, but the successful use of rituximab in pediatric patients has been increasingly reported in the literature.

Rituximab is contraindicated during pregnancy and it should also be avoided in lactating women. Until further safety data of rituximab in pregnancy are available, contraception is recommended for 12 months after the last application in the drug label. ${ }^{44}$

\section{Experience of rituximab in Chinese patients with RA}

Rituximab is indicated for the treatment of lymphoma in our locality. It was only approved to be a subsidized item in public hospitals for the treatment of RA after 2009. A small open-label study was conducted by our group in $2007 .{ }^{91}$ Ten Chinese patients with RA were recruited (age 49 years; RA duration 7.4 years; DAS28 score 7.1 \pm 0.7 ). The median number of DMARDs failed before rituximab was four and two patients had failed anti-TNF $\alpha$ treatment (one failed infliximab and the other failed both infliximab and etanercept). Patients were given rituximab $1,000 \mathrm{mg}$ by intravenous infusion on Day 1 and Day 15. Routine premedications (intravenous glucocorticoids and antihistamines) were not 
given unless patients developed infusion reactions. While MTX or LEF was continued in combination with rituximab, other DMARDs were washed out at least 4 weeks prior to study entry. At week 24, there was a significant drop in tender joint count, swollen joint count, erythrocyte sedimentation rate, C-reactive protein, and disability scores in the patients, which were associated with a significant improvement in the Short Form (36) Health Survey score. EULAR moderate/ good response was achieved in $60 \%$ of patients. Only one patient experienced a minor infusion reaction in the form of transient and mild urticarial skin rash after the first and second dose of rituximab.

Rituximab has also been successfully used for the treatment of other autoimmune diseases such as lupus nephritis and refractory dermatomyositis in our locality. ${ }^{92,93}$ In mainland China, rituximab is usually used in RA patients who do not respond adequately to the anti-TNF biologics. A recent cost-effectiveness analysis reported that infliximab and rituximab appeared to be cost-effective biological agents for moderate to severe DMARD refractory RA in mainland China based on their cost and adjusted efficacy data derived from the Western literature. ${ }^{94}$

Although rituximab is a drug of choice for lymphoma and refractory autoimmune diseases in the Asian Pacific countries, its overall usage is unclear because of a general lack of published postmarketing surveys and registries in this region of the world. The Hong Kong Biologics Registry was established in 2005 to capture safety data of various biologics for the treatment of rheumatic diseases in Hong Kong. ${ }^{95}$ According to the updated information in 2013, ${ }^{96}$ among 2,059 courses of biologics in 1,345 patients with autoimmune diseases, rituximab only accounted for $4.3 \%$ of the overall usage. Users were predominantly RA patients (98\%) because this is the only subsidized indication for rituximab. The serious infection rate in rituximab users was 1.06 per 100 patient years, which was lower than that reported in the literature. ${ }^{66,67}$ No cases of reactivation of TB or hepatitis B or $\mathrm{C}$ were reported. However, as reporting to our registry is on a voluntary basis and only RA patients are subsidized to use rituximab, underestimation of the usage and the serious infection rate of rituximab is possible.

\section{Conclusion}

Rituximab is an effective and relatively safe biological agent in the treatment of RA. It is an option to be considered in patients who are refractory or intolerant to the anti-TNF biologics. While the most cost-effective dosing and retreatment schedule remains to be defined, data on the long-term safety of rituximab are needed. Infusion reactions appear to be a disadvantage of the drug when compared to other available biological agents, but their incidence is reduced with glucocorticoid premedication and in subsequent infusions. The immunogenicity of rituximab does not seem to correlate with efficacy or the incidence of infusion reactions. The effect of rituximab-induced hypogammaglobulinemia on the long-term risk of serious infections and malignancies has to be further explored. More data are needed on the efficacy and safety of rituximab for the treatment of RA in Chinese patients.

\section{Disclosure}

The author reports no conflicts of interest in this work. The author of this article has not received any research grants or speakers' honorarium from Hoffman-La Roche related to rituximab. No writing assistance was provided by any source for this review article.

\section{References}

1. McInnes IB, Schett G. The pathogenesis of rheumatoid arthritis. NEngl J Med. 2011;365(23):2205-2219.

2. Fox DA, Gizinski A, Morgan R, Lundy SK. Cell-cell interactions in rheumatoid arthritis synovium. Rheum Dis Clin North Am. 2010;36(2): 311-323.

3. Choy E. Understanding the dynamics: pathways involved in the pathogenesis of rheumatoid arthritis. Rheumatology (Oxford). 2012;51 Suppl 5: v3-v11.

4. Klareskog L, Malmström V, Lundberg K, Padyukov L, Alfredsson L. Smoking, citrullination and genetic variability in the immunopathogenesis of rheumatoid arthritis. Semin Immunol. 2011;23(2):92-98.

5. Scher JU. B-cell therapies for rheumatoid arthritis. Bull NYU Hosp Jt Dis. 2012;70(3):200-203.

6. Panayi GS. B cells: a fundamental role in the pathogenesis of rheumatoid arthritis? Rheumatology (Oxford). 2005;44 Suppl 2:ii3-ii7.

7. Takemura S, Klimiuk PA, Braun A, Goronzy JJ, Weyand CM. T cell activation in rheumatoid synovium is B cell dependent. J Immunol. 2001;167(8):4710-4718.

8. Roosnek E, Lanzavecchia A. Efficient and selective presentation of antigen-antibody complexes by rheumatoid factor B cells. J Exp Med. 1991;173(2):487-489.

9. Marston B, Palanichamy A, Anolik JH. B cells in the pathogenesis and treatment of rheumatoid arthritis. Curr Opin Rheumatol. 2010;22(3): 307-315.

10. Kaser A, Dunzendorfer S, Offner FA, et al. B lymphocyte-derived IL-16 attracts dendritic cells and Th cells. J Immunol. 2000;165(5): 2474-2480.

11. Edwards JC, Cambridge G, Abrahams VM. Do self-perpetuating B lymphocytes drive human autoimmune disease? Immunology. 1999;97(2):188-196.

12. Corsiero E, Bombardieri M, Manzo A, Bugatti S, Uguccioni M, Pitzalis C. Role of lymphoid chemokines in the development of functional ectopic lymphoid structures in rheumatic autoimmune diseases. Immunol Lett. 2012;145(1-2):62-67.

13. Rosengren S, Wei N, Kalunian KC, Kavanaugh A, Boyle DL. CXCL13: a novel biomarker of B-cell return following rituximab treatment and synovitis in patients with rheumatoid arthritis. Rheumatology (Oxford). 2011;50(3):603-610.

14. Leandro MJ, Becerra-Fernandez E. B-cell therapies in established rheumatoid arthritis. Best Pract Res Clin Rheumatol. 2011;25(4): $535-548$. 
15. Pescovitz MD. Rituximab, an anti-cd20 monoclonal antibody: history and mechanism of action. Am J Transplant. 2006;6(5 Pt 1): $859-866$.

16. Vos K, Thurlings RM, Wijbrandts CA, van Schaardenburg D, Gerlag DM, Tak PP. Early effects of rituximab on the synovial cell infiltrate in patients with rheumatoid arthritis. Arthritis Rheum. 2007;56(3): 772-778.

17. Leandro MJ, Cooper N, Cambridge G, Ehrenstein MR, Edwards JC. Bone marrow B-lineage cells in patients with rheumatoid arthritis following rituximab therapy. Rheumatology (Oxford). 2007;46(1):29-36.

18. Roll P, Palanichamy A, Kneitz C, Dorner T, Tony HP. Regeneration of B cell subsets after transient B cell depletion using anti-CD20 antibodies in rheumatoid arthritis. Arthritis Rheum. 2006;54(8):2377-2386.

19. Vital EM, Rawstron AC, Dass S, et al. Reduced-dose rituximab in rheumatoid arthritis: efficacy depends on degree of B cell depletion. Arthritis Rheum. 2011;63(3):603-608.

20. Thurlings RM, Vos K, Wijbrandts CA, Zwinderman AH, Gerlag DM, Tak PP. Synovial tissue response to rituximab: mechanism of action and identification of biomarkers of response. Ann Rheum Dis. 2008;67(7): 917-925.

21. Gottenberg JE, Ravaud P, Bardin T, et al; AutoImmunity and Rituximab registry and French Society of Rheumatology. Risk factors for severe infections in patients with rheumatoid arthritis treated with rituximab in the autoimmunity and rituximab registry. Arthritis Rheum. 2010;62(9):2625-2632.

22. Edwards JC, Cambridge G. Sustained improvement in rheumatoid arthritis following a protocol designed to deplete B lymphocytes. Rheumatology (Oxford). 2001;40(2):205-211.

23. De Vita S, Zaja F, Sacco S, De Candia A, Fanin R, Ferraccioli G. Efficacy of selective B cell blockade in the treatment of rheumatoid arthritis: evidence for a pathogenetic role of B cells. Arthritis Rheum. 2002;46(8):2029-2033.

24. Kneitz C, Wilhelm M, Tony HP. Improvement of refractory rheumatoid arthritis after depletion of B cells. Scand J Rheumatol. 2004;33(2): 82-86.

25. Edwards JC, Szczepanski L, Szechinski J, et al. Efficacy of B-celltargeted therapy with rituximab in patients with rheumatoid arthritis. N Engl J Med. 2004;350(25):2572-2581.

26. Emery P, Fleischmann R, Filipowicz-Sosnowska A, et al; DANCER Study Group. The efficacy and safety of rituximab in patients with active rheumatoid arthritis despite methotrexate treatment: results of a phase IIB randomized, double-blind, placebo-controlled, dose-ranging trial. Arthritis Rheum. 2006;54(5):1390-1400.

27. Rubbert-Roth A, Tak PP, Zerbini C, et al; MIRROR Trial Investigators. Efficacy and safety of various repeat treatment dosing regimens of rituximab in patients with active rheumatoid arthritis: results of a Phase III randomized study (MIRROR). Rheumatology (Oxford). 2010;49(9): 1683-1693.

28. Emery P, Deodhar A, Rigby WF, et al. Efficacy and safety of different doses and retreatment of rituximab: a randomised, placebo-controlled trial in patients who are biological naive with active rheumatoid arthritis and an inadequate response to methotrexate (Study Evaluating Rituximab's Efficacy in MTX iNadequate rEsponders (SERENE)). Ann Rheum Dis. 2010;69(9):1629-1635.

29. Cohen SB, Emery P, Greenwald MW, et al.; REFLEX Trial Group. Rituximab for rheumatoid arthritis refractory to anti-tumor necrosis factor therapy: Results of a multicenter, randomized, double-blind, placebo-controlled, phase III trial evaluating primary efficacy and safety at twenty-four weeks. Arthritis Rheum. 2006;54(9):2793-2806.

30. Mease PJ, Cohen S, Gaylis NB, et al. Efficacy and safety of retreatment in patients with rheumatoid arthritis with previous inadequate response to tumor necrosis factor inhibitors: results from the SUNRISE trial. J Rheumatol. 2010;37(5):917-927.

31. Tak PP, Rigby WF, Rubbert-Roth A, et al; IMAGE Investigators. Inhibition of joint damage and improved clinical outcomes with rituximab plus methotrexate in early active rheumatoid arthritis: the IMAGE trial. Ann Rheum Dis. 2011;70(1):39-46.
32. Greenwald MW, Shergy WJ, Kaine JL, Sweetser MT, Gilder K, Linnik MD. Evaluation of the safety of rituximab in combination with a tumor necrosis factor inhibitor and methotrexate in patients with active rheumatoid arthritis: results from a randomized controlled trial. Arthritis Rheum. 2011;63(3):622-632.

33. Cohen SB, Keystone E, Genovese MC, et al. Continued inhibition of structural damage over 2 years in patients with rheumatoid arthritis treated with rituximab in combination with methotrexate. Ann Rheum Dis. 2010;69(6):1158-1161.

34. Haraoui B, Bokarewa M, Kallmeyer I, Bykerk VP; RESET Investigators. Safety and effectiveness of rituximab in patients with rheumatoid arthritis following an inadequate response to 1 prior tumor necrosis factor inhibitor: the RESET Trial. J Rheumatol. 2011;38(12): 2548-2556.

35. Gomez-Reino JJ, Maneiro JR, Ruiz J, Roselló R, Sanmarti R, Romero AB; MIRAR Study Group. Comparative effectiveness of switching to alternative tumour necrosis factor (TNF) antagonists versus switching to rituximab in patients with rheumatoid arthritis who failed previous TNF antagonists: the MIRAR Study. Ann Rheum Dis. 2012;71(11):1861-1864.

36. Tak PP, Rigby W, Rubbert-Roth A, et al. Sustained inhibition of progressive joint damage with rituximab plus methotrexate in early active rheumatoid arthritis: 2-year results from the randomised controlled trial IMAGE. Ann Rheum Dis. 2012;71(3):351-357.

37. Genovese MC, Cohen S, Moreland L, et al; 20000223 Study Group. Combination therapy with etanercept and anakinra in the treatment of patients with rheumatoid arthritis who have been treated unsuccessfully with methotrexate. Arthritis Rheum. 2004;50(5):1412-1419.

38. Weinblatt M, Combe B, Covucci A, Aranda R, Becker JC, Keystone E. Safety of the selective costimulation modulator abatacept in rheumatoid arthritis patients receiving background biologic and nonbiologic disease-modifying antirheumatic drugs: A one-year randomized, placebo-controlled study. Arthritis Rheum. 2006;54(9):2807-2816.

39. Assmann G, Pfreundschuh M, Voswinkel J. Rituximab in patients with rheumatoid arthritis and vasculitis-associated cutaneous ulcers. Clin Exp Rheumatol. 2010;28(1 Suppl 57):81-83.

40. Chandra PA, Margulis Y, Schiff C. Rituximab is useful in the treatment of Felty's syndrome. Am J Ther. 2008;15(4):321-322.

41. Iaccheri B, Androudi S, Bocci EB, Gerli R, Cagini C, Fiore T. Rituximab treatment for persistent scleritis associated with rheumatoid arthritis. Ocul Immunol Inflamm. 2010;18(3):223-225.

42. Bredemeier M, de Oliveira FK, Rocha CM. Low- versus high-dose rituximab for rheumatoid arthritis: A systematic review and metaanalysis. Arthritis Care Res (Hoboken). 2013

43. Baker JF, Ostergaard M, Emery P, et al. Early MRI measures independently predict 1-year and 2-year radiographic progression in rheumatoid arthritis: secondary analysis from a large clinical trial. Ann Rheum Dis. 2013.

44. Buch MH, Smolen JS, Betteridge N, et al; Rituximab Consensus Expert Committee. Updated consensus statement on the use of rituximab in patients with rheumatoid arthritis. Ann Rheum Dis. 2011;70(6):909-920.

45. Bastian H, Zinke S, Egerer K, et al. Effects of early rituximab retreatment in rheumatoid arthritis patients with an inadequate response after the first cycle: retrospective arthritis cohort study. J Rheumatol. 2010;37(5):1069-1071.

46. Chatzidionysiou K, Lie E, Nasonov E, et al. Effectiveness of diseasemodifying antirheumatic drug co-therapy with methotrexate and leflunomide in rituximab-treated rheumatoid arthritis patients: results of a 1-year follow-up study from the CERERRA collaboration. Ann Rheum Dis. 2012;71(3):374-377.

47. Chatzidionysiou K, Lie E, Nasonov E, et al. Highest clinical effectiveness of rituximab in autoantibody-positive patients with rheumatoid arthritis and in those for whom no more than one previous TNF antagonist has failed: pooled data from 10 European registries. Ann Rheum Dis. 2011;70(9):1575-1580.

48. Dass S, Rawstron AC, Vital EM, Henshaw K, McGonagle D, Emery P. Highly sensitive B cell analysis predicts response to rituximab therapy in rheumatoid arthritis. Arthritis Rheum. 2008;58(10):2993-2999. 
49. Narvaez J, Díaz-Torné C, Ruiz JM, et al. Predictors of response to rituximab in patients with active rheumatoid arthritis and inadequate response to anti-TNF agents or traditional DMARDs. Clin Exp Rheumatol. 2011;29(6):991-997.

50. Couderc M, Mathieu S, Pereira B, Glace B, Soubrier M. Predictive factors of rituximab response in rheumatoid arthritis: results from a French university hospital. Arthritis Care Res (Hoboken). 2013;65(4):648-652.

51. Sellam J, Hendel-Chavez H, Rouanet S, et al. B cell activation biomarkers as predictive factors for the response to rituximab in rheumatoid arthritis: a six-month, national, multicenter, open-label study. Arthritis Rheum. 2011;63(4):933-938.

52. Lal P, Su Z, Holweg CT, et al. Inflammation and autoantibody markers identify rheumatoid arthritis patients with enhanced clinical benefit following rituximab treatment. Arthritis Rheum. 2011;63(12): 3681-3691.

53. Nakou M, Katsikas G, Sidiropoulos P, et al. Rituximab therapy reduces activated $\mathrm{B}$ cells in both the peripheral blood and bone marrow of patients with rheumatoid arthritis: depletion of memory B cells correlates with clinical response. Arthritis Res Ther. 2009;11(4):R131.

54. Leandro MJ, Cambridge G, Ehrenstein MR, Edwards JC. Reconstitution of peripheral blood B cells after depletion with rituximab in patients with rheumatoid arthritis. Arthritis Rheum. 2006;54(2):613-620.

55. Möller B, Aeberli D, Eggli S, et al. Class-switched B cells display response to therapeutic B-cell depletion in rheumatoid arthritis. Arthritis Res Ther. 2009;11(3):R62.

56. Ruyssen-Witrand A, Rouanet S, Combe B, et al. Fc $\gamma$ receptor type IIIA polymorphism influences treatment outcomes in patients with rheumatoid arthritis treated with rituximab. Ann Rheum Dis. 2012;71(6) $875-877$.

57. Ruyssen-Witrand A, Rouanet S, Combe B, et al. Association between $-871 \mathrm{C}>\mathrm{T}$ promoter polymorphism in the B-cell activating factor gene and the response to rituximab in rheumatoid arthritis patients. Rheumatology (Oxford). 2013;52(4):636-641.

58. Fabris M, Quartuccio L, Lombardi S, et al. The CC homozygosis of the $-174 \mathrm{G}>\mathrm{C}$ IL-6 polymorphism predicts a lower efficacy of rituximab therapy in rheumatoid arthritis. Autoimmun Rev. 2012;11(5): 315-320.

59. Sellam J, Rouanet S, Hendel-Chavez H, et al. Blood memory B cells are disturbed and predict the response to rituximab in patients with rheumatoid arthritis. Arthritis Rheum. 2011;63(12):3692-3701.

60. Sellam J, Rouanet S, Hendel-Chavez H, et al. CCL19, a B cell chemokine, is related to the decrease of blood memory B cells and predicts the clinical response to rituximab in patients with rheumatoid arthritis. Arthritis Rheum. 2013;65(9):2253-2261.

61. Owczarczyk K, Lal P, Abbas AR, et al. A plasmablast biomarker for nonresponse to antibody therapy to CD20 in rheumatoid arthritis. Sci Transl Med. 2011;3(101):101ra92.

62. van Vollenhoven RF, Emery P, Bingham CO 3rd, et al. Longterm safety of patients receiving rituximab in rheumatoid arthritis clinical trials $J$ Rheumatol. 2010;37(3):558-567.

63. Kimby E. Tolerability and safety of rituximab (MabThera). Cancer Treat Rev. 2005;31(6):456-473.

64. Salliot C, Dougados M, Gossec L. Risk of serious infections during rituximab, abatacept and anakinra treatments for rheumatoid arthritis meta-analyses of randomised placebo-controlled trials. Ann Rheum Dis. 2009;68(1):25-32.

65. Curtis JR, Xie F, Chen L, et al. The comparative risk of serious infections among rheumatoid arthritis patients starting or switching biological agents. Ann Rheum Dis. 2011;70(8):1401-1406.

66. van Vollenhoven RF, Emery P, Bingham CO, et al. Long-term safety of rituximab in rheumatoid arthritis: 9.5-year follow-up of the global clinical trial programme with a focus on adverse events of interest in RA patients. Ann Rheum Dis. 2013;72(9):1496-1502.

67. Keystone E, Fleischmann R, Emery P, et al. Safety and efficacy of additional courses of rituximab in patients with active rheumatoid arthritis: an open-label extension analysis. Arthritis Rheum. 2007;56(12): 3896-3908.
68. Casulo C, Maragulia J, Zelenetz AD. Incidence of hypogammaglobulinemia in patients receiving rituximab and the use of intravenous immunoglobulin for recurrent infections. Clin Lymphoma Myeloma Leuk. 2013;13(2):106-111.

69. Otremba MD, Adam SI, Price CC, Hohuan D, Kveton JF. Use of intravenous immunoglobulin to treat chronic bilateral otomastoiditis in the setting of rituximab induced hypogammaglobulinemia. $\mathrm{Am} \mathrm{J}$ Otolaryngol. 2012;33(5):619-622.

70. Pyrpasopoulou A, Douma S, Vassiliadis T, Chatzimichailidou S, Triantafyllou A, Aslanidis S. Reactivation of chronic hepatitis B virus infection following rituximab administration for rheumatoid arthritis. Rheumatol Int. 2011;31(3):403-404.

71. Gigi E, Georgiou T, Mougiou D, Boura P, Raptopoulou-Gigi M. Hepatitis $B$ reactivation in a patient with rheumatoid arthritis with antibodies to hepatitis B surface antigen treated with rituximab. Hippokratia. 2013;17(1):91-93.

72. Ghrénassia E, Mékinian A, Rouaghe S, Ganne N, Fain O. Reactivation of resolved hepatitis B during rituximab therapy for rheumatoid arthritis. Joint Bone Spine. 2012;79(1):100-101.

73. Chen YM, Chen HH, Lai KL, Hung WT, Lan JL, Chen DY. The effects of rituximab therapy on released interferon- $\gamma$ levels in the QuantiFERON assay among RA patients with different status of Mycobacterium tuberculosis infection. Rheumatology (Oxford). 2013;52(4):697-704.

74. Gheuens S, Wüthrich C, Koralnik IJ. Progressive multifocal leukoencephalopathy: why gray and white matter. Annu Rev Pathol. 2013;8:189-215.

75. Gheuens S, Pierone G, Peeters P, Koralnik IJ. Progressive multifocal leukoencephalopathy in individuals with minimal or occult immunosuppression. J Neurol Neurosurg Psychiatry. 2010;81(3):247-254.

76. Clifford DB, Ances B, Costello C, et al. Rituximab-associated progressive multifocal leukoencephalopathy in rheumatoid arthritis. Arch Neurol. 2011;68(9):1156-1164.

77. Fleischmann RM. Progressive multifocal leukoencephalopathy following rituximab treatment in a patient with rheumatoid arthritis. Arthritis Rheum. 2009;60(11):3225-3228.

78. Bharat A, Xie F, Baddley JW, et al. Incidence and risk factors for progressive multifocal leukoencephalopathy among patients with selected rheumatic diseases. Arthritis Care Res (Hoboken). 2012;64(4): 612-615.

79. Arkema EV, van Vollenhoven RF, Askling J; ARTIS Study Group. Incidence of progressive multifocal leukoencephalopathy in patients with rheumatoid arthritis: a national population-based study. Ann Rheum Dis. 2012;71(11):1865-1867.

80. Sugauchi F, Tanaka Y, Kusumoto S, et al. Virological and clinical characteristics on reactivation of occult hepatitis B in patients with hematological malignancy. J Med Virol. 2011;83(3):412-418.

81. Fukushima N, Mizuta T, Tanaka M, et al. Retrospective and prospective studies of hepatitis B virus reactivation in malignant lymphoma with occult HBV carrier. Ann Oncol. 2009;20(12):2013-2017.

82. Hsu C, Tsou HH, Lin SJ, et al.; Taiwan Cooperative Oncology Group. Chemotherapy-induced hepatitis B reactivation in lymphoma patients with resolved HBV infection: A prospective study. Hepatology. 2013.

83. Ennishi D, Yokoyama M, Terui Y, et al. Does rituximab really induce hepatitis C virus reactivation? J Clin Oncol. 2008;26(28):4695-4696; author reply 4696

84. Dizdar O, Tapan U, Aksoy S, Harputluoglu H, Kilickap S, Barista I. Liver dysfunction after chemotherapy in lymphoma patients infected with hepatitis C. Eur J Haematol. 2008;80(5):381-385.

85. Sagnelli E, Pisaturo M, Sagnelli C, Coppola N. Rituximab-based treatment, HCV replication, and hepatic flares. Clin Dev Immunol. 2012;2012:945950.

86. Oren S, Mandelboim M, Braun-Moscovici Y, et al. Vaccination against influenza in patients with rheumatoid arthritis: the effect of rituximab on the humoral response. Ann Rheum Dis. 2008;67(7):937-941.

87. van Assen S, Holvast A, Benne CA, et al. Humoral responses after influenza vaccination are severely reduced in patients with rheumatoid arthritis treated with rituximab. Arthritis Rheum. 2010;62(1):75-81. 
88. Rehnberg M, Brisslert M, Amu S, Zendjanchi K, Håwi G, Bokarewa MI. Vaccination response to protein and carbohydrate antigens in patients with rheumatoid arthritis after rituximab treatment. Arthritis Res Ther. 2010;12(3):R111.

89. Arad U, Tzadok S, Amir S, et al. The cellular immune response to influenza vaccination is preserved in rheumatoid arthritis patients treated with rituximab. Vaccine. 2011;29(8):1643-1648.

90. Bingham CO 3rd, Looney RJ, Deodhar A, et al. Immunization responses in rheumatoid arthritis patients treated with rituximab: results from a controlled clinical trial. Arthritis Rheum. 2010;62(1):64-74.

91. Ho LY, Mok CC, To CH, Anselm M, Cheung MY, Yu KL. Rituximab for refractory rheumatoid arthritis: a 24-week open-label prospective study. Open Rheumatol J. 2007;1:1-4.

92. Mok CC, Ho LY, To CH. Rituximab for refractory polymyositis: an open-label prospective study. J Rheumatol. 2007;34(9):1864-1868.
93. Li EK, Tam LS, Zhu TY, et al. Is combination rituximab with cyclophosphamide better than rituximab alone in the treatment of lupus nephritis? Rheumatology (Oxford). 2009;48(8):892-898.

94. Wu B, Wilson A, Wang FF, et al. Cost effectiveness of different treatment strategies in the treatment of patients with moderate to severe rheumatoid arthritis in china. PLoS One. 2012;7(10):e47373.

95. Mok CC, Kwan C, Chan KY, et al. Retention rate of the anti-TNF biologics in the treatment of rheumatic diseases and predictive factors for drug withdrawal: data from the Hong Kong Biologics Registry. [abstract]. Arthritis Rheum. 2012;64 Suppl 10:388.

96. Mok CC, Chan KY, Lee KL, et al. Factors associated with withdrawal of the anti-TNF $\alpha$ biologics in the treatment of rheumatic diseases: data from the Hong Kong Biologics Registry. Int J Rheum Dis. 2013 [in press].

\section{Publish your work in this journal}

Drug Design, Development and Therapy is an international, peerreviewed open-access journal that spans the spectrum of drug design and development through to clinical applications. Clinical outcomes, patient safety, and programs for the development and effective, safe, and sustained use of medicines are a feature of the journal, which has also been accepted for indexing on PubMed Central. The manuscript management system is completely online and includes a very quick and fair peer-review system, which is all easy to use. Visit http://www.dovepress.com/testimonials.php to read real quotes from published authors.

Submit your manuscript here: http://www.dovepress.com/drug-design-development-and-therapy-journal 